\title{
LAVERDI, Robson; MASTRÁNGELO, Mariana. (Compiladores). Desde las profundidades de la historia oral. Buenos Aires: Imago Mundi, 2013. 293 p.
}

\author{
Suzana Bitencourt *
}

Paul Thompson, no livro $A$ Voz do Passado (1992), pontua que a história oral é tão antiga quanto a própria história, considerando-a, de fato, a primeira espécie de história. Para justificar este argumento, apoia-se no impressionante relato de Jules Michelet, que, ao escrever sobre a História da Revolução Francesa (184753), tinha, não apenas no punho, mas também na mente que os documentos eram apenas uma das possibilidades de fontes para compreensão do movimento que culminou com a queda da Bastilha. No fundo, Michelet valia-se da própria memória, pois, tendo nascido em Paris dez anos antes da queda da Bastilha, colheu sistematicamente evidências orais fora de sua cidade natal. Seu objetivo era contrapor documentos oficiais com as evidências surgidas da tradição popular.

O livro Desde las Profundidades da Historia Oral (2013), organizado por Robson Laverdi e Mariana Mastrángelo, envereda-se pelo mesmo caminho. Os resultados das pesquisas mostram relatos de experiências, comentam cotidianos e confrontam documentos oficiais com fontes de origem oral, emprestando outro sentido ao ato de fazer história. Abordando variados temas e problemas, enfatizam protagonistas esquecidos e histórias não contadas, abrangendo uma gama de temáticas e problemáticas, motivo pelo qual podemos chamar de recente historiografia da história oral. É importante ressaltar que a obra compila a produção de um conjunto de historiadores de países vizinhos, como Argentina, Brasil e Uruguai, pesquisadores que compõem a Red Latinoamericana de História (RELAHO), criada em 2010, cujo principal objetivo é agregar pesquisadores que produzem com base em oralidades. A RELAHO também pretende manter o intercâmbio de pesquisas em história oral, pondo em circulação o conhecimento produzido oralmente. Do mesmo modo, a RELAHO consolida um espaço de encontros acadêmicos e discussões, visando integrar pesquisadores que se dedicam a história oral na América Latina.

O livro está organizado em três partes, compreendidas pelos organizadores como eixos temáticos: Teorias da história oral; História oral, memória e política; e História oral, identidades e experiências sociais. No dizer dos organizadores, a intenção é ser uma das referências atuais no que se refere à história oral como categoria de análise, enriquecendo os estudos em ciências sociais, trazendo

\footnotetext{
* Mestre em História Cultural pela Universidade Federal de Santa Catarina. Doutoranda do Programa de Pós-Graduação em Educação da Universidade Estadual de Ponta Grossa. E-mail: <suzanazero@gmail.com>
} 
à tona personagens esquecidos e histórias não contadas, ou ainda, recontadas porque animadas pelas fontes de origem oral.

Notadamente, as fontes de origem oral tornam-se, na obra, mais do que um mero recurso metodológico que enriquece a produção historiográfica. Tal qual indicou Paul Thompson, elas são entendidas como uma forma de transmissão anterior ao escrito, uma maneira de construir fontes. Nesse sentido, os artigos revelam - a partir de canções populares, lendas, contos transmitidos de geração para geração, compondo representações e desvelando experiências cotidianas - modos de vida comum, que, em certa medida, fazem parte da história de uma parcela dos povos que compõem a América Latina.

No primeiro eixo, "Teorias da história oral", temos o artigo do historiador Eudes Leite, que, refletindo sobre a produção histórica e historiográfica no Brasil, procura compreender o significado da oralidade na história oral. Como afirma Leite, oralidade é o núcleo central da história oral, porque é a partir das fontes orais que podemos entender as práticas sociais e históricas. Nessa direção, considera que a oralidade, quando desencadeada pela ação de lembrar, possui tanta relevância quanto possui a própria memória.

Ainda no primeiro eixo, o artigo de Luiz Felipe Falcão reflete sobre a utilização da história oral na prática do historiador contemporâneo para compreender como tal metodologia pode servir para inventar o passado. A ilusão da verdade em história oral lembra Falcão, pode ser comparada com as miragens, que criam e inventam ambientes. Tais inventos são coerentes e passam a ser tratados como fato e efeito, revelados pelas fontes orais e entendidos como reais.

Fechando o primeiro eixo, o artigo de Robson Laverdi, buscando aproximações com a produção do crítico literário inglês Raymond Williams e as práticas de história oral na contemporaneidade, destaca a linguagem e a estrutura de sentimentos como categorias pertencentes à produção histórica. Nas palavras de Laverdi, o instante da entrevista não pode limitar a produção da fonte como produto da pesquisa; há muito mais a ser observado pelo pesquisador. Nesse sentido, a linguagem é parte de um processo social que aproxima entrevistado e entrevistador, e a historicidade presente no encontro para a entrevista não encerra as possibilidades e objetivos que se pretende alcançar, pois a individualização e a socialização são indissociáveis e se constituem por meio da linguagem. Os signos linguísticos apontados por Raymond Williams colocam as relações sociais em movimento, deixando de ser simples reflexos ou expressões da realidade, como sugerido pelo marxismo ortodoxo. No dizer de Laverdi, tal percepção é significativa para a história oral porque revelam sentidos subjetivos resultantes da linguagem na forma de testemunho oral. Isso significa que a produção do testemunho oral não pode ser reduzida à entrevista; ela pode significar uma 
conexão entre o individual e o social, envolvendo o entrevistado e o entrevistador, denotando uma experiência dinâmica articulada e emprestando outro sentido diferente daquele pretendido pela tradição da história oral, cujo indicativo queria apenas dar voz aos esquecidos. As fontes de origem oral levadas a efeito pela história oral, resignificadas pela linguagem - como aponta Williams -, deixam de ser apenas um método para marcar uma posição na direção do restabelecimento de um processo social histórico.

No segundo eixo, "História oral, memória e política", os artigos são dedicados à história recente da ditadura militar na Argentina. As produções surgidas a partir das fontes de origem oral emprestam novo sentido àqueles acontecimentos. Primeiramente, o relato da experiência do Grupo de Investigação sobre o Genocídio em Tucumán - GIGET, coordenado por Ana Sofía Jemio e Alejandra Pisani, resgata os testemunhos das classes populares que sofreram com a ditadura militar. As seguir, o artigo de Laura Ortiz discorre sobre as percepções dos operários e das operárias a respeito de um acontecimento ocorrido na cidade de Córdoba. O estudo de Adriana Echuzeri e María Rosa Loiácono explica contextualizando a função da paróquia de Santa Cruz no bairro portenho de São Cristovão durante a ditadura. Na sequência, o artigo de Ángeles Anchou reflete sobre a motivação das freiras de Assunção - Buenos Aires, quando estas abriram a igreja para classes sociais menos favorecidas, no intuito de integrá-las ao colégio de elite que administravam.

Este eixo temático termina com uma extraordinária entrevista coletiva com Clara Aldrighi, professora de História Contemporânea da Faculdade de Humanidades e Ciências da Educação na Universidade de Montevidéu, realizada no Brasil, em 2011, por Marcos Nestor Stein, Paulo José Koling e Robson Laverdi, abordando temas da história recente do Uruguai.

Notadamente, o que há em comum entre os artigos reunidos no segundo eixo temático não é apenas e tão somente um olhar de historiadores sobre a década de 1970, época de repressão política e esmagamento da expressão popular argentina. Os relatos sugerem as potencialidades da história oral, em que os temas e problemas investigados ganham contornos próprios visibilizados pelas experiências dos envolvidos, construindo novas formas de pensar o processo histórico, bem como novas fontes são cotejadas para a produção do conhecimento histórico.

Méri Frotscher abre o terceiro e último eixo, "História oral, identidades e experiências sociais", trazendo uma consistente discussão sobre a importância das complexas relações entre língua e identidade a partir de relatos de imigrantes. Destacando que o objetivo principal do artigo é discutir como os imigrantes narram suas vivências durante o exato momento da entrevista, e por qual língua 
se expressam, com os possíveis significados e utilizações que podem direcionar para distintos elementos de interpretação e, portanto, compreensão. Entrevistando imigrantes alemães no Brasil, entre os que vieram da Alemanha nacional-socialista e também os que foram repatriados depois da Segunda Guerra Mundial, o artigo denota as alterações comportamentais em situações de entrevistas. Embora o alemão não seja a língua pátria da autora do artigo, o fato de compreender fluentemente o idioma favoreceu a relação entre entrevistada e entrevistadora, destaca Frotscher, de onde surge uma pertinente discussão.

É neste eixo que encontramos também uma ampla e comovente entrevista realizada por Mónica Gatica e Gonzalo Pérez Álvarez, em Trelew, de onde são oriundos os pesquisadores. Ani, como se referem os pesquisadores à entrevistada, é uma legendária militante de esquerda, que também viveu seus últimos dias em Trelew. A militante contribuiu para a organização da classe operária em Buenos Aires e, assim que ficou desempregada, organizou os trabalhadores desocupados da província de Chubut.

Em continuidade, temos a história mais do que original de Iara, uma transexual da região de Matanza que chegou a se conscientizar da luta política, aderindo ao grupo sobre o sugestivo nome Agrupación Putos Peronistas de la Matanza. Os autores Gerardo Alberto Médica e Viviana Villegas resgatam a história de Iara desde as "profundezas da pobreza", para utilizar as palavras dos próprios autores do artigo.

Para finalizar o eixo, o trabalho de Maria Andréa Angelotti Carmo busca compreender os significados e os sentidos em determinado grupo de trabalhadores rurais em categorias distintas no que se refere a trabalho agrícola, na intenção de entender a problemática das migrações do campo para a cidade no Brasil contemporâneo.

Por tudo quanto foi exposto, o livro em questão não é apenas um esforço de agregar pesquisadores dos países circunvizinhos da América Latina. É também uma ação criativa e renovada para publicações de pesquisas que utilizam a história oral como fonte. Os artigos e suas problemáticas de pesquisa inspiram outras pesquisas, contribuindo assim com novas abordagens para o ensino de História, tão carente de renovações.

Como recomenda Paul Thompson, em $A$ voz do passado, a história oral, para que se torne um instrumento de mudança, depende do sentido em que é utilizada. Os autores reunidos em Das profundezas da história oral souberam muito bem utilizar o espírito do referido apontamento.

\section{Referência}

THOMPSON, P. A voz do passado: história oral. Rio de Janeiro: Paz e Terra, 1992. 